\title{
Fuzzy Logic Method Design for Landslide Vulnerability
}

\author{
Made Dandy Wardhana ${ }^{1, *}$, Aghus Sofwan $^{2}$, and Iwan Setiawan ${ }^{2}$ \\ ${ }^{1}$ Magister Program of Electrical Engineering, Diponegoro University, Semarang - Indonesia \\ ${ }^{2}$ Department of Electrical Engineering, Faculty of Engineering, Diponegoro University, Semarang - Indonesia
}

\begin{abstract}
Landslide is one of the most frequently happened disasters in Indonesia due to weather and climate characteristics, regional topography, and geological structures that make this country have many potential landslide areas. The main goal of this study is to apply fuzzy logic to the landslide detection sensor so that it is easier to find out areas prone to landslides. The fuzzy logic method uses five parameters to analyze the landslide area. These parameters are rainfall, land slope, moisture content in two different soil depths, and ground vibration. They are used to determine the vulnerability level of landslide area is very safe, relatively safe, relatively potential, potentially and very potential. Fuzzification, inference, and defuzzification performed on each data in the analysis process to determine the vulnerability of landslides, and the parameters and weighting rules are according to government regulations. From the results of the study, it was concluded that intelligent systems based on fuzzy logic can be used to determine the level of vulnerability of landslides in a specified area.
\end{abstract}

Keywords: Fuzzy logic; Landslide; Vulnerability; Early warning.

\section{Introduction}

Landslides often occur in Indonesia due to weather and climate characteristics, regional topography, and geological structures that make this country have many potential landslide areas. Especially when continuous rain in a short period of time tends to trigger a rapid flow of shallow mud and debris. The cause of landslides can occur because Indonesia has a tropical monsoon climate, which is caused by changes in extreme air pressure in the Indian mainland and Indian Ocean [1]. Complex geological and geographical conditions and changes in climate conditions in time and space produce landslides. An increase in sudden external factors such as earthquakes, high rainfall causes landslides [2]. As for some causes of landslides that can be used as parameters in the system for determining the level of vulnerability of landslides. These factors can be used as a reference as a parameter to calculate the level of vulnerability of landslides. This parameter is taken based on reference to the Minister of Public Works Regulation No.22 / PRT / M / 2007 (PMPU No.22 / PRT / M / 2007) [3] with some adjustments as the basis for manual calculations. The causes include slope, rainfall/hour, soil moisture and ground vibration.

There are other factors that also become the calculation of the occurrence of disasters, such as slope, ground vibration, etc. The process of identifying these causal factors is needed to determine the effect of each factor on the occurrence of a landslide disaster.

The slope will increase the driving force causing the landslide. The steep slopes are formed due to the erosion of river water, rainwater, and wind. In rainfall factors, a long dry season will cause large amounts of water to evaporate on the surface. This high rainfall causes increased deepwater content and eventually triggers a landslide [4]. Soil moisture is the amount of water concentration in the soil. This is caused by evaporation through the soil surface, transpiration, and percolation. Measuring the level of soil moisture is carried out on the soil surface and inside the soil surface. Whereas in the ground vibration it can cause landslides because of the vibration there can be a shift between the soil. The introduction of patterns of changes in the value of each of these factors when a landslide occurs will facilitate the prediction of a landslide disaster. A system is needed that can identify various factors that cause landslides to detect signs of landslides.

\subsection{Literature Review}

At present, there is a lot of research on how to detect the vulnerability of landslides. One of them is research on the design of wireless sensor networks for landslide early warning based on the internet of things [5]. In this study, a tool was used to collect data using several sensors to detect soil moisture, soil slope, humidity, and temperature. The results obtained in the form of sensor data in the form of data on soil moisture, soil slope, humidity, and temperature. The measured data is obtained for 9 hours.

There is a study about the input of early warning landslides built into the system is the movement of rocks, debris or soil to the slopes [6]. The focus of this

\footnotetext{
* Corresponding author: madedandy@students.undip.ac.id
} 
study is on the warning of the general population together with disaster management authorities in the event of a landslide. The server is programmed using PHP and XAMPP which continuously monitors incoming data from Zigbee installed on COM ports. Data is sent with a server to an android application specifically designed to alert users immediately after a landslide occurs. In this study only using an accelerometer that can measure the degree of 3-axis slope of each axis, where the tool is considered not enough to measure the factor of occurrence of landslides.

Basofi (2017) [7], regarding the mapping of landslide vulnerability in Ponorogo village in the area using fuzzy logic and natural breakdown classification [7]. In this fuzzy logic method, five variables are used to detect the most vulnerable areas. These variables are land slope, soil type, land use, rainfall, and land height. The vulnerability of landslides consists of very low, low, medium or high. The method used to compare the results of validation is chi-squared calculations. As a result of this calculation, for the classification of AHP natural breaks, the total values of fuzzy logic are 92,576 and 184,917 each. It can be concluded from two validation methods that the relationship between the classification of landslide vulnerability and landslide itself has a very significant relationship. The AHP method of natural chisquared results in better validation results even though both methods are very significant.

Hizrian (2018), artificial neural network designs were made using advanced cascade-backpropagation methods [8]. 5 input parameters are given to this artificial neural network method which can be measured by MPU 6050 sensor, rainfall is measured by bucket tipping sensor with reed switch, water content at two soil depths is different from FC-28 humidity sensor, and ground measured by vibration with 801 s sensor. This system has an output in the form of calculating the possibility of landslides in areas that are safe, alert and dangerous. The results of this artificial neural network method will be compared with the output of the advanced feed backpropagation method to determine its performance.

Giri (2018) [9], presents a wireless sensor network system (WSNS) for effective, reliable and efficient landslide monitoring [9]. The system incorporates a network of wireless Inertial Measurement Unit (IMU) sensor devices for collecting movement data, local base stations for data collection, capture servers for data processing and storage, and warning systems. The main contributions of this paper are three, namely two approaches to determining movement limits, the concept of classification of landslides based on the pattern and magnitude of the IMU sensor data and the conceptual framework for building intelligent and reliable wireless monitoring and warning systems. The results of this research paper serve as a basis for future studies and technological advances that will facilitate the action of landslide stabilization or mitigation and to predict the intensity of damage associated with the landslide.

Umar (2013) [10], presents the results of soil data in the laboratory using soil taken from the location of landslides and using the software SLOPE/W from
Geoslope to obtain the amount of rainfall that caused the landslides [10]. This is done to reduce the casualty of landslides due to the large earthquake that was followed by heavy rainfall. A simple early warning system based on the rainfall threshold that causes landslides can be done by the community themselves. The result, to determine the rainfall data, each group consisting of 10 s/d 20 houses located around the hills should install one rainfall gauge, which is operated by the community, and at the time of heavy rain, officers appointed by the group should always look for high rain on the rainfall gauges periodically or every one hour. If the rain has reached a high level of danger, all residents must leave the area.

An early warning system aims to avoid and reduce the risk of damage and casualties caused by natural disasters [11]. The objective of this research is to develop landslide and earthquake early warning system applications for smartphone devices with Android operating system. This research uses crowdsourcing data collection from smartphone with low-cost sensors able to detect movement. Despite less accuracy than scientific instruments, but the ubiquity of smartphone can cover a larger area. This research uses Agile method to develop an early warning system on Android device. Research activities are conducted in 6 (six) phases: requirement, plan, design, develop, release, track \& monitor.

Fernandez (2016), the objective is to develop a landslide early warning system that utilizes rain gauge and an intelligent accelerometer/inclinometer for interception of the possible occurrence of landslide [12]. With the help of PHIVOLCS and PAGASA calibration for the standard level of measurement were established: (1) rainfall amount,(2) angular displacement and (3) ground movement. With the factors observed it is expected to deliver an effective landslide early warning system that can intercept an impending landslide whether it is earthquake-induced or rain-induced.

By referring to several journal results, using the concept of fuzzy logic is easier than the artificial neural network method, but in research that uses fuzzy data, the data used is mapping data in a particular area. And in studies using artificial neural network methods, parameters are obtained from the results of measured sensors in real-time. This study aims to apply fuzzy logic to the landslide detection sensor so that it is easier to find out areas prone to landslides. It is expected that the method can provide more accurate results compared to the previous method.

Fuzzy logic is an increase of Boolean logic which deals with the concept of partial truth. Boolean logic states that everything can be expressed in binary terms $(0$ or 1, yes or no), fuzzy logic is used to replace boolean logic with a partial level of truth. Fuzzy logic allows membership values between 0 and 1 to be described in linguistic form or uncertain concepts such as "little", "decent", and "very". This logic is related to the theory of possibility. Fuzzy logic was introduced by Dr. Lotfi Zadeh from the University of California, Berkeley in 1965 [13].

The use of fuzzy methods can be done in early landslide detection systems because fuzzy intelligent systems can describe, know, and model the processes of 
human thinking and design a system in order to mimic human behavior. The fuzzy process consists of three stages, fuzzification, inference, and defuzzification. It is expected that the level of accuracy in determining the level of landslide vulnerability is more accurate and precise.

\section{Methodology}

The basic system of the landslide vulnerability response system is shown in Figure 1. To analyze the landslide vulnerability index variable, a fuzzy logic system is used. To produce a landslide warning alert as a response from the database, it is done from the assessment of landslide susceptibility.

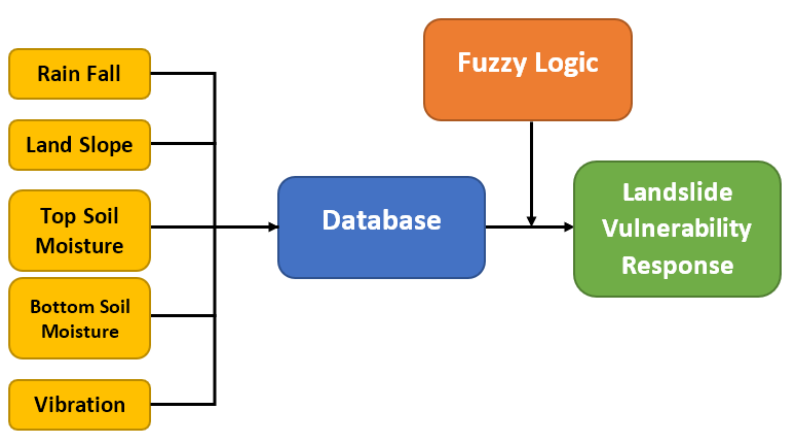

Fig. 1. System design

Figure 1 is a system diagram, and a detailed description of it is as follows:

- The initial data are raw data from previous research. To support the decision-making system, the data obtained will be processed.

- After that, the data enters the database and retrieves data from the database and then processed using fuzzy logic to support vulnerability to landslide responses.

- The next process is processing data from the base and showing it to be the level of vulnerability of the landslide.

\subsection{Landslide susceptibility using Fuzzy Logic}

To identify landslide vulnerability areas, fuzzy logic methods are used which have 5 criteria, consists of rainfall, soil slope, topsoil moisture, bottom soil moisture, and vibration as shown in Figure 1. These criteria have a relationship between data variables and landslides based on previous research on landslides. All variables in each criterion will be processed using a fuzzy logic system. The fuzzy logic system has three stages, namely fuzzification, inference, and defuzzification. The fuzzification process is a process of mapping the input value (crisp input) originating from a system that is controlled in accordance with the fuzzy set membership function. After the fuzzification process, the inference process will process the fuzzification output which is determined by fact data from experts or institutions and is presented in logical sentences in the form of rules. After the calculation of each variable has been done, the last process carried out is the defuzzification process. All combinations of variables will be compared with evaluating existing rules resulting in a degree of vulnerability to landslides.

For an explanation of the value of linguistic variables can be seen as follows:

- Rainfall variable has three linguistic value: low, medium, and high.

- Land slope variable has three linguistic values: flat, sloping and steep.

- Topsoil moisture variable has three linguistic values: low, medium, and high.

- Bottom soil moisture variable has three linguistic value: low, medium, and high.

- Land vibration variable has three linguistic values: low, high, very high.

There are numbers from each linguistic value in the variables listed in PMPU as seen in Table 1.

Table 1. Value of linguistic variables.

\begin{tabular}{|c|c|c|c|}
\hline No & Variable & \multicolumn{2}{|c|}{ Criteria } \\
\hline \multirow{3}{*}{1} & \multirow{3}{*}{$\begin{array}{l}\text { Rainfall/hour } \\
\text { (weight } 15 \% \text { ) }\end{array}$} & $0-30$ & Low \\
\hline & & $30-70$ & Medium \\
\hline & & $>70$ & High \\
\hline \multirow{3}{*}{2} & \multirow{3}{*}{$\begin{array}{c}\text { Landslope } \\
\text { (weight 30\%) }\end{array}$} & $0-20$ & Flat \\
\hline & & $20-40$ & Sloping \\
\hline & & $>40$ & Steep \\
\hline \multirow{3}{*}{3} & \multirow{3}{*}{$\begin{array}{c}\text { Top soil } \\
\text { moisture } \\
\text { (weight } 15 \% \text { ) }\end{array}$} & $0-30$ & Low \\
\hline & & $30-40$ & Medium \\
\hline & & $>40$ & High \\
\hline \multirow{3}{*}{4} & \multirow{3}{*}{$\begin{array}{c}\text { Bottom soil } \\
\text { moisture } \\
\text { (weight } 20 \% \text { ) }\end{array}$} & $0-30$ & Low \\
\hline & & $30-40$ & Medium \\
\hline & & $>40$ & High \\
\hline \multirow{3}{*}{5} & \multirow{3}{*}{$\begin{array}{c}\text { Vibration } \\
\text { (weight } 20 \% \text { ) }\end{array}$} & $0-2$ & Low \\
\hline & & $3-5$ & Medium \\
\hline & & $>5$ & High \\
\hline
\end{tabular}

\subsection{Fuzzification}

The linguistic values on each variable can be categorized from the classification data based on the value of each variable. Each variable value has been determined according to the Minister of Public Works Regulation. Linguistic values represented in graphical form are shown in Figure 3 to Figure 7.

\subsubsection{Rainfall}

Rainfall has a $15 \%$ weight in the occurrence of landslides. Figure 2 is about rainfall graphs with values for each classification interval consisting of low, medium and high. 


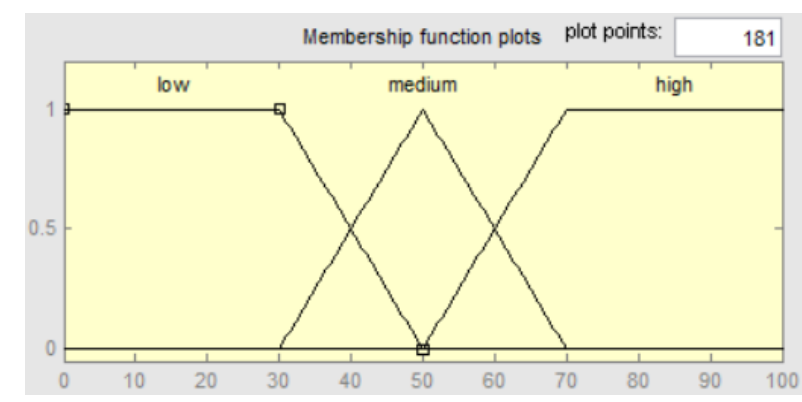

Fig. 2. Rainfall graph

\subsubsection{Land slope}

Land slope has a greater weight, which is $30 \%$. Therefore this category has a large impact because the average landslide occurs due to the very steep land slope. Figure 3 is about land slope graphs with the value of each classification interval that consists of flat, sloping and steep.

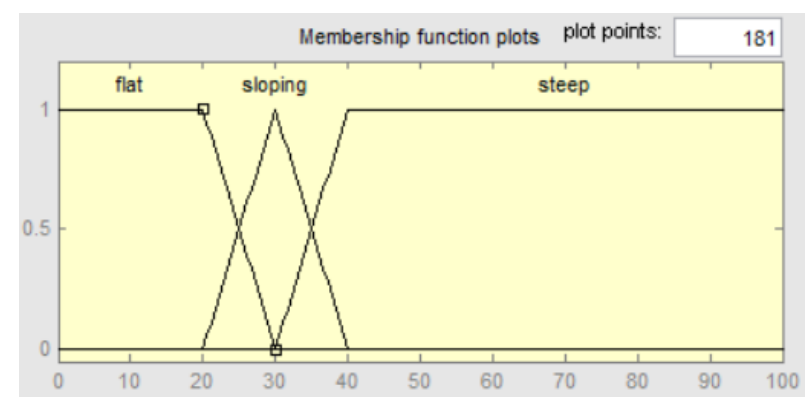

Fig. 3. Land slope graph

\subsubsection{Topsoil moisture}

Topsoil moisture has a $15 \%$ weight in the occurrence of landslides. Figure 4 is about topsoil moisture graph with the value of each classification interval that consists of low, medium and high.

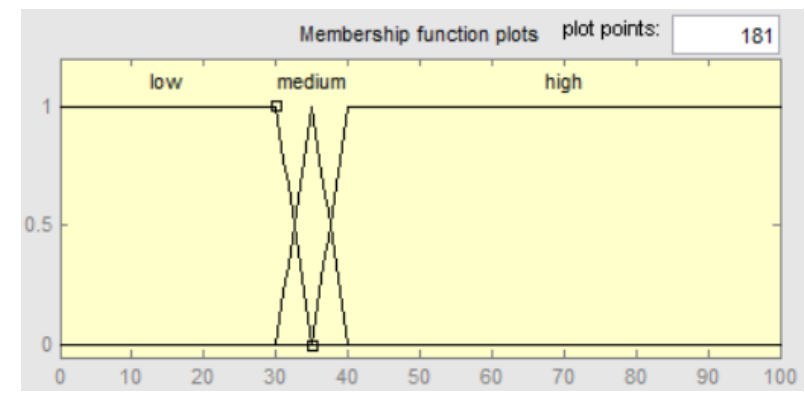

Fig. 4. Topsoil moisture graph

\subsubsection{Bottom soil moisture}

Bottom soil moisture is about to same with bottom soil moisture, the difference is data retrieval. Figure 5 is about bottom soil moisture graph with the value of each classification interval that consists of low, medium and high.

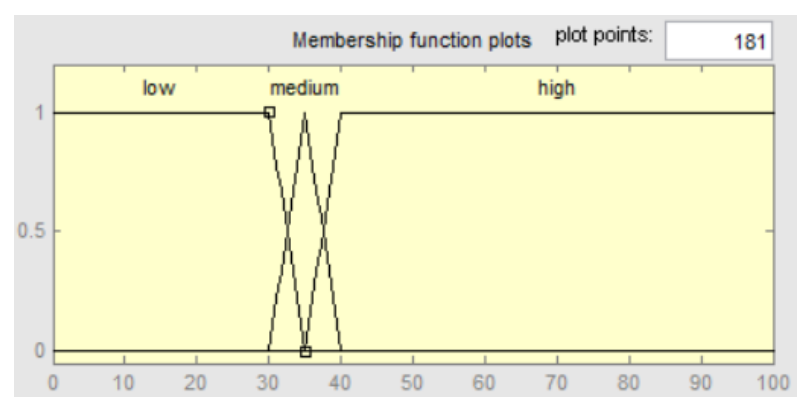

Fig. 5. Bottom soil moisture graph

\subsubsection{Vibration}

Vibration has a $20 \%$ weight in the occurrence of landslides. This category is the second largest weight after land slope because vibrations that occur such as earthquakes can cause landslides. Figure 6 is about vibration graph with the value of each classification interval that consists of low, medium and high.

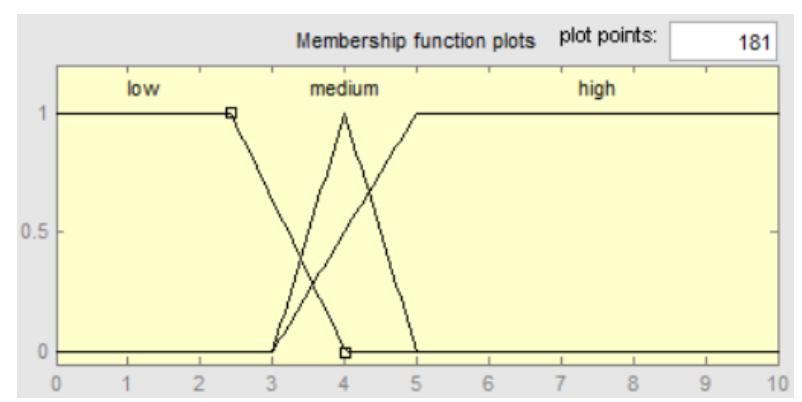

Fig. 6. Vibration graph

\subsection{Evaluation Rule}

References and guidelines for determining evaluation rules are shown in Table 2. This evaluation rule was developed based on rules approach and correlation calculation to find variable priorities. Thus, after the process, evaluation of rules was developed into 33 evaluation rules. 
Table 2. Evaluation rule.

\begin{tabular}{|c|c|c|c|c|c|c|}
\hline No & $\begin{array}{l}\text { Rain } \\
\text { Fall }\end{array}$ & $\begin{array}{l}\text { Land } \\
\text { Slope }\end{array}$ & $\begin{array}{c}\text { Top } \\
\text { Soil } \\
\text { Moistu } \\
\text { re } \\
\end{array}$ & $\begin{array}{c}\text { Bottom } \\
\text { Soil } \\
\text { Moisture }\end{array}$ & $\begin{array}{c}\text { Vibratio } \\
\mathbf{n}\end{array}$ & $\begin{array}{l}\text { vulnerability } \\
\text { of landslide }\end{array}$ \\
\hline 1 & Low & Flat & $\begin{array}{c}\text { Mediu } \\
\text { m }\end{array}$ & High & Low & $\begin{array}{l}\text { Relatively } \\
\text { potential }\end{array}$ \\
\hline 2 & Low & Flat & High & High & High & $\begin{array}{l}\text { Relatives } \\
\text { potential }\end{array}$ \\
\hline 3 & Low & Flat & Low & High & Medium & $\begin{array}{l}\text { Relatively } \\
\text { safe }\end{array}$ \\
\hline 4 & Low & Flat & $\begin{array}{c}\text { Mediu } \\
\mathrm{m}\end{array}$ & Medium & High & $\begin{array}{l}\text { Relatively } \\
\text { safe }\end{array}$ \\
\hline 5 & Low & Flat & Low & Medium & Medium & $\begin{array}{c}\text { Relatively } \\
\text { safe }\end{array}$ \\
\hline 6 & $\begin{array}{c}\text { Mediu } \\
\mathrm{m}\end{array}$ & Steep & Low & Medium & High & potential \\
\hline 7 & Low & Flat & Low & Medium & Medium & $\begin{array}{l}\text { Relatively } \\
\text { safe }\end{array}$ \\
\hline 8 & Low & Flat & Low & High & Medium & $\begin{array}{c}\text { Relatively } \\
\text { safe }\end{array}$ \\
\hline 9 & Low & Flat & Low & Low & Medium & Very safe \\
\hline 10 & Low & Flat & High & Low & High & $\begin{array}{l}\text { Relatively } \\
\text { safe }\end{array}$ \\
\hline 11 & High & Sloping & \begin{tabular}{|c|} 
Mediu \\
$\mathrm{m}$
\end{tabular} & High & High & Potential \\
\hline 12 & $\begin{array}{c}\text { Mediu } \\
\mathrm{m}\end{array}$ & Steep & High & Medium & Medium & Potential \\
\hline 13 & Low & Flat & Low & High & Medium & $\begin{array}{c}\text { Relatively } \\
\text { safe }\end{array}$ \\
\hline 14 & Low & Steep & $\begin{array}{c}\text { Mediu } \\
\text { m }\end{array}$ & High & High & Potential \\
\hline 15 & $\begin{array}{c}\text { Mediu } \\
\mathrm{m}\end{array}$ & Steep & $\begin{array}{c}\text { Mediu } \\
\mathrm{m}\end{array}$ & Low & High & Potential \\
\hline 16 & Low & Flat & ow & Low & High & $\begin{array}{l}\text { Relatively } \\
\text { safe }\end{array}$ \\
\hline 17 & Low & Sloping & Low & High & High & $\begin{array}{l}\text { Relatively } \\
\text { Potential }\end{array}$ \\
\hline 18 & Low & Flat & High & Medium & Medium & $\begin{array}{c}\text { Relatively } \\
\text { safe }\end{array}$ \\
\hline 19 & Low & Flat & $\begin{array}{c}\text { Mediu } \\
\text { m }\end{array}$ & Low & Medium & Very safe \\
\hline 20 & $\begin{array}{c}\text { Mediu } \\
\mathrm{m}\end{array}$ & Sloping & High & High & High & Potential \\
\hline 21 & Low & Flat & Low & High & High & $\begin{array}{c}\text { Relatively } \\
\text { Potential }\end{array}$ \\
\hline 22 & Low & Flat & $\begin{array}{c}\text { Mediu } \\
\text { m }\end{array}$ & Medium & Iigh & $\begin{array}{c}\text { Relatively } \\
\text { safe }\end{array}$ \\
\hline 23 & $\begin{array}{c}\text { Mediu } \\
\mathrm{m}\end{array}$ & Steep & Low & Medium & High & Potential \\
\hline 24 & Low & Flat & High & Medium & Iigh & $\begin{array}{l}\text { Relatively } \\
\text { Potential }\end{array}$ \\
\hline 25 & Low & Sloping & Low & Medium & Medium & $\begin{array}{l}\text { Relatively } \\
\text { safe }\end{array}$ \\
\hline 26 & Low & Sloping & Low & Med & ligh & $\begin{array}{l}\text { Relatively } \\
\text { Potential }\end{array}$ \\
\hline 27 & Low & eep & High & & Iigh & Very potential \\
\hline 28 & Low & Steep & High & Medium & High & Potential \\
\hline 29 & $\begin{array}{c}\text { Mediu } \\
\mathrm{m}\end{array}$ & Steep & High & Medium & High & Very potential \\
\hline 30 & $\begin{array}{c}\text { Mediu } \\
\mathrm{m}\end{array}$ & Steep & ow & Medium & ligh & otential \\
\hline 31 & Low & Flat & Low & Low & Low & Very safe \\
\hline 32 & Low & Flat & \begin{tabular}{|c|} 
Mediu \\
$\mathrm{m}$
\end{tabular} & High & High & $\begin{array}{c}\text { Relatively } \\
\text { Potential }\end{array}$ \\
\hline 33 & Low & Flat & $\begin{array}{c}\text { Mediu } \\
\text { m }\end{array}$ & Low & Medium & Very safe \\
\hline
\end{tabular}

\subsection{Defuzzification}

In this process, defuzzification process is used to find fuzzy membership. From each variable as rainfall, slope, top soil moisture, bottom soil moisture, and vibration will be found fuzzy membership level. 5 variables will be obtained as the output level of the combination of variable combinations that have been calculated using fuzzy logic. There are 5 classifications of output levels that are very safe, relatively safe, potential, relatively potential, and very potential.

\section{Result and Discussion}

In this section, we provide the measurement results of fuzzy logic calculation. The calculation has been done on the 33 data from previous research which each of them need to process into fuzzy logic calculation. Data measurement is shown in Table 3.

Table 3. Data measurement.

\begin{tabular}{|c|c|c|c|c|c|}
\hline Data & $\begin{array}{c}\text { Rain } \\
\text { fall }\end{array}$ & $\begin{array}{l}\text { Land } \\
\text { Slope }\end{array}$ & $\begin{array}{c}\text { Top Soil } \\
\text { Moisture } \\
\end{array}$ & $\begin{array}{c}\text { Bottom Soil } \\
\text { Moisture }\end{array}$ & $\begin{array}{c}\text { Vibra- } \\
\text { tion }\end{array}$ \\
\hline 1 & 22 & 6 & 31 & 83 & 0 \\
\hline 2 & 7 & 7 & 45 & 81 & 7 \\
\hline 3 & 7 & 0 & 2 & 84 & 5 \\
\hline 4 & 9 & 12 & 35 & 35 & 6 \\
\hline 5 & 26 & 9 & 23 & 33 & 3 \\
\hline 6 & 57 & 46 & 2 & 35 & 7 \\
\hline 7 & 3 & 0 & 12 & 32 & 4 \\
\hline 8 & 7 & 0 & 23 & 83 & 3 \\
\hline 9 & 25 & 5 & 18 & 8 & 4 \\
\hline 10 & 12 & 5 & 87 & 21 & 6 \\
\hline 11 & 93 & 21 & 32 & 51 & 7 \\
\hline 12 & 40 & 73 & 69 & 35 & 4 \\
\hline 13 & 22 & 19 & 20 & 57 & 4 \\
\hline 14 & 19 & 68 & 35 & 84 & 7 \\
\hline 15 & 32 & 41 & 33 & 13 & 6 \\
\hline 16 & 26 & 6 & 20 & 25 & 6 \\
\hline 17 & 11 & 27 & 15 & 71 & 7 \\
\hline 18 & 29 & 4 & 88 & 39 & 5 \\
\hline 19 & 15 & 12 & 33 & 1 & 3 \\
\hline 20 & 34 & 31 & 64 & 82 & 7 \\
\hline 21 & 21 & 11 & 19 & 93 & 6 \\
\hline 22 & 3 & 0 & 30 & 35 & 6 \\
\hline 23 & 31 & 95 & 6 & 36 & 7 \\
\hline 24 & 14 & 15 & 43 & 31 & 7 \\
\hline 25 & 21 & 35 & 3 & 34 & 4 \\
\hline 26 & 15 & 37 & 23 & 35 & 7 \\
\hline 27 & 0 & 64 & 95 & 70 & 6 \\
\hline 28 & 2 & 85 & 55 & 32 & 6 \\
\hline 29 & 51 & 96 & 82 & 31 & 6 \\
\hline 30 & 57 & 46 & 2 & 35 & 7 \\
\hline 31 & 9 & 5 & 21 & 8 & 0 \\
\hline 32 & 11 & 1 & 32 & 81 & 6 \\
\hline 33 & 4 & 5 & 35 & 26 & 5 \\
\hline
\end{tabular}


Measurements are made using analysis of data processing results, which is by comparing the reality of the data with the results of system detection. Real probability is the possibility of landslides based on the results of reality made based on rules in accordance with the reality and presentation of each variable on the potential of landslides and the system probability is the output of the fuzzy logic system that has been made. There are 7 data results that have differences, which is the difference is very small. What is meant by very small is the vulnerability of potential landslides does not have a far gap. The results of data comparisons between real probability and probability systems can be seen in Table 4.

Table 4. Comparison of data results.

\begin{tabular}{|c|c|c|}
\hline Data & Real probability & System Probability \\
\hline 1 & relative potential & relative potential \\
\hline 2 & relative potential & relative potential \\
\hline 3 & relative safe & relative potential \\
\hline 4 & relative safe & relative safe \\
\hline 5 & relative safe & very safe \\
\hline 6 & potential & potential \\
\hline 7 & relative safe & very safe \\
\hline 8 & relative safe & relative potential \\
\hline 9 & very safe & very safe \\
\hline 10 & relative safe & relative safe \\
\hline 11 & potential & potential \\
\hline 12 & potential & potential \\
\hline 13 & relative safe & relative safe \\
\hline 14 & potential & potential \\
\hline 15 & potential & potential \\
\hline 16 & relative safe & relative safe \\
\hline 17 & relative potential & relative potential \\
\hline 18 & relative safe & relative potential \\
\hline 19 & very safe & very safe \\
\hline 20 & potential & potential \\
\hline 21 & relative potential & relative potential \\
\hline 22 & relative safe & relative safe \\
\hline 23 & potential & potential \\
\hline 24 & relative potential & relative safe \\
\hline 25 & relative safe & relative safe \\
\hline 26 & relative potential & relative potential \\
\hline 27 & very potential & very potential \\
\hline 28 & potential & potential \\
\hline 29 & very potential & very potential \\
\hline 30 & potential & potential \\
\hline 31 & very safe & very safe \\
\hline 32 & relative potential & relative potential \\
\hline 33 & very safe & relative safe \\
\hline
\end{tabular}

\section{Conclusion}

This paper presents the proposed fuzzy logic for intelligent vulnerability warnings of landslides. Several factors that can affect the level of vulnerability to landslides are needed in the fuzzy logic method. The factors are rainfall, land slope, topsoil moisture, bottom soil moisture, and vibration. The calculation results are divided into five classifications, that is very safe, relatively safe, relative potential, potential, and very potential. The results of the landslide's vulnerability using fuzzy logic compared to the results of reality. With the 33 data collected, there are 7 different data results. The difference of $2.03 \%$ is considered quite good because the difference does not have a gap that is far from each vulnerability. So, in this case, it could be said the fuzzy logic system is working well. The more rules are given to fuzzy logic system, the more accurate the results will be.

\section{References}

1. K. Nakamura, W. A. Noerdjito, and A. Hasyim, "Regional Difference and Seasonity of Rainfall in Java," pp. 93-103, (1994)

2. A. Federico, M. Popescu, C. Fidelibus, and G. Interno, "On the prediction of the time of occurrence of a slope failure: A review," in Proc.9th Int. Symp. Landslides, 2, pp. 979-983, (2004)

3. Minister of Public Works Regulation in Indonesia No.22/PRT/M/2007. Jakarta, (2007)

4. H. L.J and L. X.S, "Study on landslide related to rainfall," J. Xiangtan Norm. Univ, 4, 22, pp. 5562, (2002)

5. A. Sofwan, M. Ridho, and A. Goni, "Wireless Sensor Network Design for Landslide Warning System in IoT Architecture," pp. 280-283, (2017)

6. S. Kapoor, H. Pahuja, and B. Singh, "Real-time monitoring \& alert system for landslide," 2016 2nd Int. Conf. Contemp. Comput. Informatics, pp. 584589, (2016)

7. A. Basofi, A. Fariza, and M. R. Dzulkarnain, "Landslides susceptibility mapping using fuzzy logic: A case study in Ponorogo, East Java, Indonesia," Proc. 2016 Int. Conf. Data Softw. Eng. ICoDSE 2016, pp. 0-6, (2017)

8. T. A. Hizrian, "Perancangan Jaringan Sensor Nirkabel Untuk Pendeteksi Dini Terjadinya Tanah Longsor Dengan Jaringan Syaraf Tiruan Multilayer Perceptron “. Teknik Elektro, Universitas Diponegoro, Semarang (2018)

9. P. Giri, K. Ng, and W. Phillips, "Wireless Sensor Network System for Landslide Monitoring and Warning," IEEE Trans. Instrum. Meas., vol. PP, pp. 1-11, (2018)

10. Z. Umar, A. Ahmad, W. Abdul, A. Wan, and M. Akib, "Early Warning System for Landslide Hazard Caused by Earthquake and Rainfall in West Sumatera Province, Indonesia," pp. 541-546, (2013)

11. A. Heryana, E. Nugraheni, B. Kusumo, A. F. Rojie, and B. Setiadi, "Applying Agile Methods in Designing an Earthquake and Landslide Early Warning System Application for Android," 1: 8084, (2017)

12. C. D. Femandez, K. J. A. Mendoza, and A. Jude, "Development of Microcontroller-based Landslide Early Warning System." IEEE Region 10 Conference, pp. 3000-3005, (2016)

13. Zadeh, L.A,Fuzzy sets, Information and Control 8 (3): 338-353, (1965) 